\title{
Cauda Equina and Filum Terminale Arteriovenous Fistulas: Anatomic and Radiographic Features
}

\author{
(D). Namba, (D). Niimi, (D). Ishiguro, (D) A. Higaki, (D) N. Toma, and (D) M. Komiyama
}

\begin{abstract}
SUMMARY: Intradural AVF below the conus medullaris may develop either on the filum terminale or the cauda equina (lumbosacral and coccygeal radicular nerves). Although not a few filum terminale AVFs are found in the literature, only 3 detailed cauda equina $A V F s$ have been reported. Here, we analyze the angiographic and MR imaging findings of our cauda equina and filum terminale AVF cases, supplemented with literature research to characterize the radiologic features of the 2 entities. On angiography, filum terminale AVFs were invariably supplied by the extension of the anterior spinal artery accompanied by a closely paralleling filum terminale vein. Cauda equina AVFs were fed by either a radicular or a spinal artery or both arteries, often with a characteristic wavy radicular-perimedullary draining vein. On thin-section axial MR imaging, the filum terminale AVF draining vein joined the spinal cord at the conus medullaris apex, but that of the cauda equina AVF joined above the conus medullaris apex.
\end{abstract}

ABBREVIATIONS: ASA = anterior spinal artery; $\mathrm{FT}=$ filum terminale

$\mathbf{T}$ he spinal canal below the conus medullaris accommodates lumbar, sacral, or coccygeal nerve roots (ie, the cauda equina) ${ }^{1}$ and the filum terminale (FT). Intradural vascular lesions in this region may affect the cauda equina or the FT. Since the pioneering work by Djindjian et $\mathrm{al}^{2}$ the FT AVF has gained wide recognition, but the cauda equina AVF is scarcely known. ${ }^{3-5}$ As such, few radiologic findings differentiating the 2 diseases are known. ${ }^{5}$

We present our cauda equina and FT AVF cases supplemented by previous reports and discuss the angiographic and MR imaging features of the 2 diseases.

Received March 22, 2020; accepted after revision June 1.

From the Center for Endovascular Therapy (K.N., A.H.), Division of

Neuroendovascular Surgery, Jichi Medical University, Tochigi, Japan; Department of Neuroendovascular Therapy (Y.N.), St. Luke's International Hospital, Tokyo, Japan; Department of Neurointervention (T.I., M.K.), Osaka City General Hospital, Osaka, Japan; and Department of Neurosurgery (N.T.), Mie University Graduate School of Medicine, Mie, Japan.

Previously presented in part at: 9th Meeting of the Niche Neuro-Angiology Conference, Osaka, Japan, May 30, 2015; 31st Annual Meeting of the Japanese Society for Neuroendovascular Therapy, Okayama, Japan, November 20, 2015; and 33rd Annual Meeting of the Japanese Society for Neuroendovascular Therapy, Tokyo, Japan, November 25, 2017.

Please address correspondence to Katsunari Namba, Center for Endovascular Therapy, Division of Neuroendovascular Surgery, Jichi Medical University, 3311-1 Yakushiji, Shimotsuke, Tochigi 329-0498, Japan; e-mail: knamba@jichi.ac.jp

Indicates article with supplemental on-line table.

http://dx.doi.org/10.3174/ajnr.A6813

\section{CASE SERIES}

\section{Patients and Imaging Features}

The study followed the policies of each institution's Research Ethics Committee. The cases were retrieved from a prospectively collected spinal vascular malformation database between November 2012 and April 2017. Four patients with cauda equina or FT AVF were identified. All patients underwent spinal angiography, including bilateral internal iliac and all appropriate segmental arteries.

To observe the ascending draining vein, a precontrast axial T2-weighted turbo spin-echo (section thickness, $4 \mathrm{~mm}$; TE, $105 \mathrm{~ms}$; TR, $5000 \mathrm{~ms}$ ) sequence and postcontrast axial T1weighted turbo spin-echo (section thickness, $4 \mathrm{~mm}$; TE, $9.30 \mathrm{~ms}$; $\mathrm{TR}, 650 \mathrm{~ms}$ ) sequence 5 minutes after a $10-\mathrm{mL}$ IV injection of gadobutrol (Gadovist; Bayer Schering Pharma) were studied on a 3T scanner (Magnetom Skyra; Siemens). Whereas the radicular vein accompanies a nerve root that is apart from the spinal cord at the conus medullaris apex, the FT vein anastomoses with the anterior spinal vein at the apex. Therefore, a draining vein off the spinal cord at the conus medullaris apex was interpreted as radicular, whereas the vein on the cord was an FT vein.

\section{Literature Review}

A PubMed search on May 1, 2019, was performed using the following terms: "cauda equina AND arteriovenous fistula," "cauda equina AND arteriovenous malformation," "filum terminale AND arteriovenous fistula," or "filum terminale AND arteriovenous malformation." The research yielded $36,62,50$, and 72 


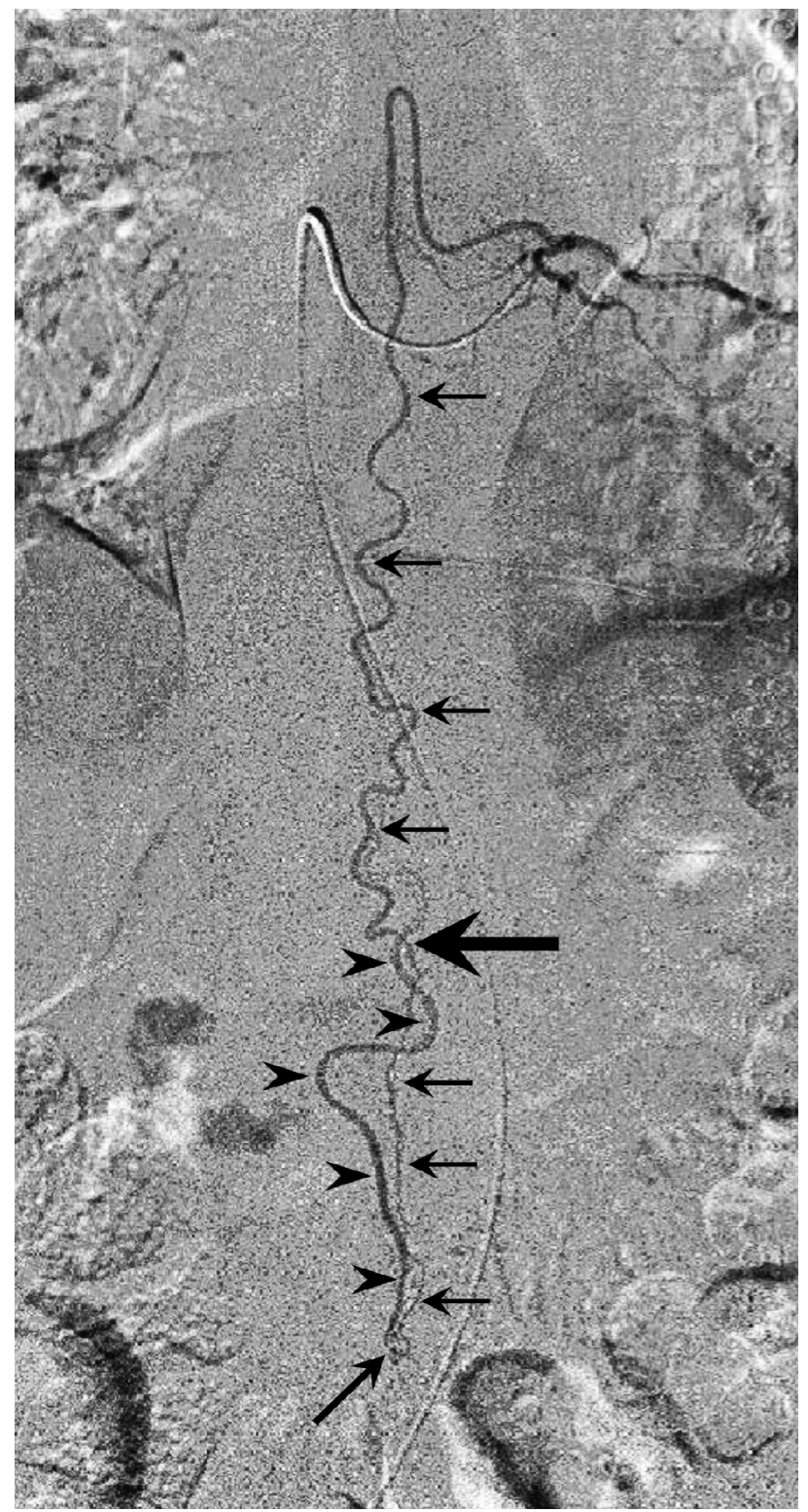

FIG 1. Left T9 intercostal artery angiogram in anteroposterior view shows the extension of the anterior spinal artery (arrows) traveling caudally to form an AVF at the L2 level (oblique arrow). The ascending draining vein shows a characteristic wavy pattern (arrowheads). Note the change in the course and caliber of the ASA at the conus medullaris apex (large arrow), suggesting a change of the feeding artery to a radicular artery. Reprinted with permission from Figure $2 \mathrm{c}$ in Tanioka S, Toma N, Sakaida H, et al. A case of AVF of the cauda equina fed by the proximal radicular artery: anatomical features and treatment precautions. Eur Spine J 2018;27(suppl 3):281-86.

articles, respectively. Only the articles containing both angiographic figures and surgical confirmation of the fistula were included. Three cauda equina ${ }^{3,5}$ and $31 \mathrm{FT}^{2,4,6-25} \mathrm{AVF}$ cases were eligible, including 1 patient in this study (case 3 ). ${ }^{5}$

\section{RESULTS}

Patient demographics, angiographic and MR imaging characteristics, and treatment outcomes are listed in the On-line Table. We diagnosed 3 cauda equina AVFs (cases 1, 2, 3) and 1 FT AVF (case 4). The FT and 2 cauda equina AVFs were treated by endovascular embolization and 1 cauda equina AVF by direct surgery. All the procedures were completed without clinical sequelae. One embolized cauda equina AVF (case 1) resulted in residual fistula, but the patient declined further treatment (case 1).

\section{Spinal Angiography}

Spinal angiography detected all the AVFs between the L2 and L4 vertebral levels. In $2 \mathrm{AVFs}$, caudal extension of the anterior spinal artery (ASA) was the single feeder (cases 3 and 4, Figs 1 and 2A), and a single right $\mathrm{S} 1$ radicular artery was the feeder in 1 (case 2, Fig $3 A$ ). Both the extension of the ASA and left $\mathrm{S} 1$ radicular artery were the feeders in 1 (case 1 , Fig $4 A,-B$ ). In cases 1 and 3 , the ASA made changes in the course and caliber at the conus medullaris apex (Figs 1 and 4, large arrow), whereas in case 4, the ASA made a straight descent without changing its caliber.

The ascending draining vein showed a wavy pattern not paralleling the feeding artery in 2 cases (cases 1 and 3, Figs $4 A$ and 1) and a straight ascent in 1 (case 2, Fig $3 A$ ) and closely paralleled the feeding artery in 1 (case 4 , Fig $2 A$ ).

Case 2 was complicated by multiple AVFs described in detail in Fig 3.

\section{MR Imaging Features}

Thin-section axial T2WI and enhanced T1WI detected the ascending draining vein in cases 1,2 , and 4 (Figs $4 C, 3 C$, and $2 B$, arrows). In cases 1 and 2, the vein was off the spinal cord at the conus medullaris apex (Figs $4 C$ and $3 C$, arrowhead) and joined it at the $\mathrm{L} 1$ level (Figs $4 C$ and $3 C$, large horizontal arrow) and thus was interpreted as radicular. In case 4 , the vein united with the cord at the conus medullaris apex (Fig 2B, arrowheads) and hence was an FT vein. In case 3, the MR imaging failed to detect the vein.

\section{DIAGNOSIS}

Based on the angiographic and MR imaging findings, the diagnosis of cauda equina AVF was made in cases 1 and 2 and FT AVF in case 4 . In case 3 , surgical findings confirmed the diagnosis of cauda equina $\mathrm{AVF} .^{5}$

\section{Literature Review}

The literature review yielded $3^{3,5}$ and $31^{2,4,6-25}$ surgically confirmed cauda equina and FT AVF cases, respectively. In all the 3 cauda equina AVF cases, the fistula was fed by a single extension of the ASA without radicular artery involvement. The ASA changed its course and caliber at the conus medullaris apex. In 2 cases, the draining vein showed a wavy pattern, but the other case paralleled the feeding artery. ${ }^{3}$

In the 31 FT AVF cases, the ASA invariably fed the fistula and maintained its straight course and robust caliber at the conus medullaris apex. All FT AVF draining veins showed the parallel feeder-drainer pattern. To date, only 4 surgically proved cases with additional radicular artery supply have been reported, ${ }^{4,10,16,24}$ and no FT AVF with exclusive radicular artery supply is known. 

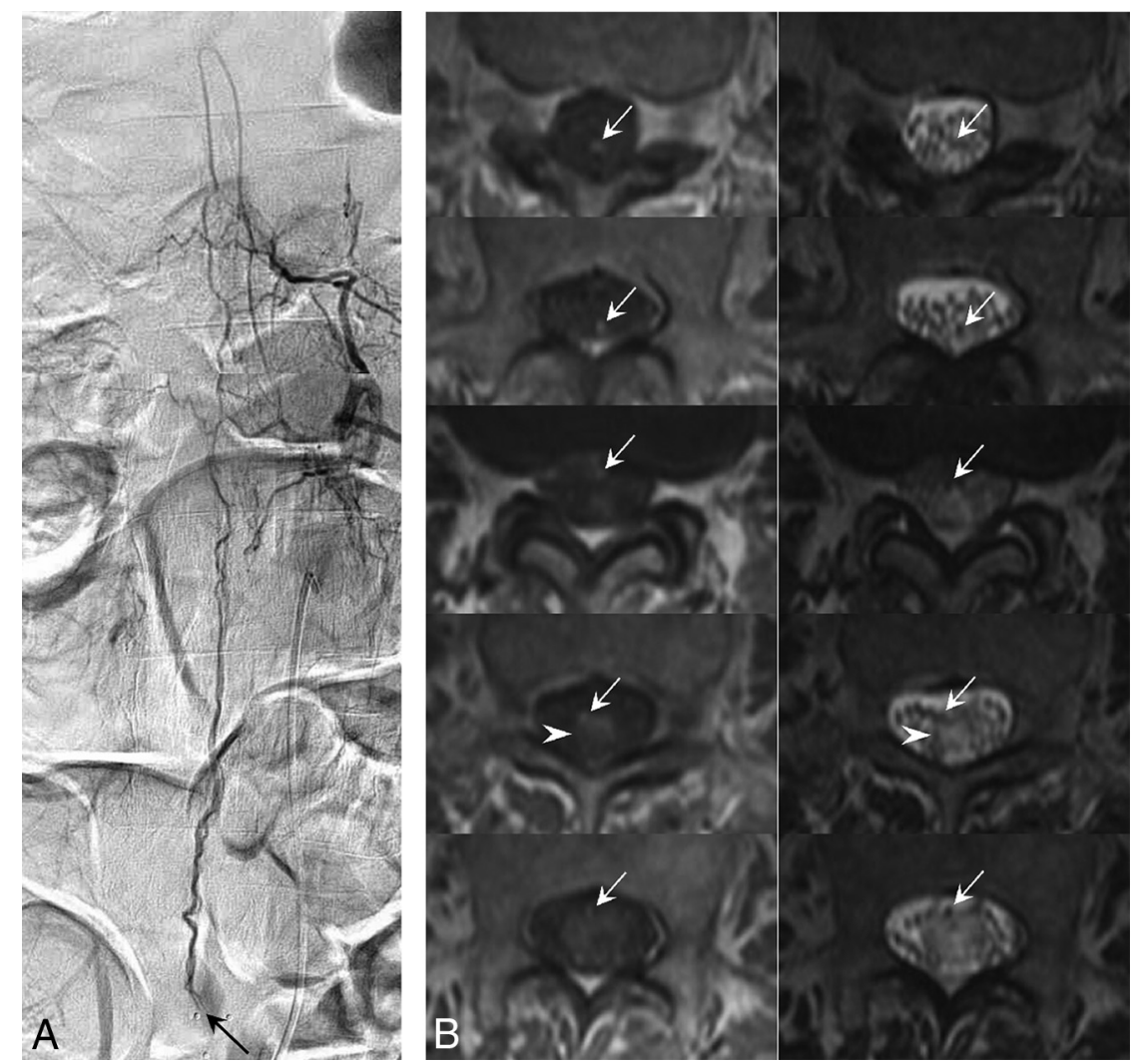

FIG 2. A, Angiogram of the left L1 lumbar artery in anteroposterior projection demonstrates a filum terminale AVF at the L4 level. The fistula (oblique arrow) is supplied by the caudal extension of the anterior spinal artery, which is the artery of the filum, and drained by the vein of the filum. The ASA does not change its course or caliber at the conus medullaris and maintains its robust caliber down to the fistula site. Note the parallel feeder and drainer pattern. B, Serial thin-section gadolinium enhanced TIWI (left column) and T2WI (right column) arranged in caudal (upper) to cranial (lower) order show the draining vein (arrows) merging with the spinal cord at the apex of the edematous conus medullaris (arrowhead). This finding suggests that this is the vein of FT.

FT. ${ }^{21,26}$ These findings may explain the characteristic parallel feeder-drainer pattern observed in all the FT AVF cases. $^{2,4,6-25}$

\section{Vascular Anatomy of the Cauda Equina and Cauda Equina AVF and Diagnostic Considerations}

The cauda equina is supplied from the segmental radicular arteries originating from the medial and lateral sacral arteries, or the iliolumbar artery. Importantly, Parke et $\mathrm{al}^{29}$ demonstrated that the proximal one-third of the radicular nerve was supplied by the spinal artery, mainly the vasa corona, and the peripheral two-thirds was supplied by the radicular artery. Consequently, the cauda equina AVF feeder could be radicular, spinal, or both.

In the literature, only 3 surgically proved and 7 angiographic cauda equina AVF cases have been reported. ${ }^{3-5}$ All 7 angiographic AVFs were reported by Hong et $\mathrm{al}^{4}$ based on the findings that the feeder was a radicular artery and the fistula was located off the midline. No spinal artery involvement was noted in their series. In contrast, in all 3 surgically proven AVFs, extension of the ASA was the sole feeder. ${ }^{3,5}$ Our results demonstrated mixed results as may be expected from the cauda equina vascular anatomy.

In cauda equina AVFs, the ASA

\section{DISCUSSION}

The main findings in the present study were 1) in the FT AVF, the ASA maintained its course and caliber at the conus medullaris apex, 2) the FT AVF showed a parallel feeder-drainer pattern, 3) the cauda equina AVF had variable feeding arteries, 4) the extension of the ASA involved in the cauda equina AVF changed its course and caliber at the conus medullaris apex, 5) the cauda equina AVF showed a wavy draining vein in 3 of 5 cases, and 6) thin-section axial MR imaging detecting the draining vein may aid in differentiating cauda equina and FT AVFs.

\section{Vascular Anatomy of the Filum Terminale and Filum Terminale AVF and Diagnostic Considerations}

Anatomically, the FT artery is the direct caudal continuation of the ASA, ${ }^{26}$ and embryologically, the FT is a remnant of the spinal cord. $^{27,28}$ Therefore, it is reasonable that the cardinal feeder of the FT AVF should be the extension of the ASA (FT artery), and the ASA maintained a straight course and robust caliber at the conus medullaris apex.

Normal and pathologic AVF sections of the FT showed the FT artery and vein existing side by side throughout the length of the showed changes in the caliber and course at the conus medullaris apex. These changes may reflect the transition of the ASA into a radicular artery and were observed only in the cauda equina AVF and thus may be pathognomonic findings.

The radicular arteries are bound loosely to their nerve filaments by filmy pia arachnoid, ${ }^{30}$ and this may be similar for the veins. This loose connection may explain the wavy drainage vein pattern seen in 3 of the 5 cauda equina AVF cases. Because the feeder-drainer is always parallel in the FT AVF, the wavy drainer pattern may also be pathognomonic for cauda equina AVF.

Thin-section axial MR imaging detected the draining vein in 3 of 4 cases. A draining vein joining the spinal cord above the conus medullaris apex (Figs $4 C$ and $3 C$ ) was especially suggestive of a radicular vein. In case 3 , in which the MR imaging failed in vein detection, the examination was conducted within 1 month after a transient paraparesis. We presume that the lesion was premature for MR imaging detection.

\section{CLINICAL RELEVANCE}

Accurate fistula diagnosis is crucial in treating spinal AVFs. This prevents disorientation during surgical exploration and incomplete 

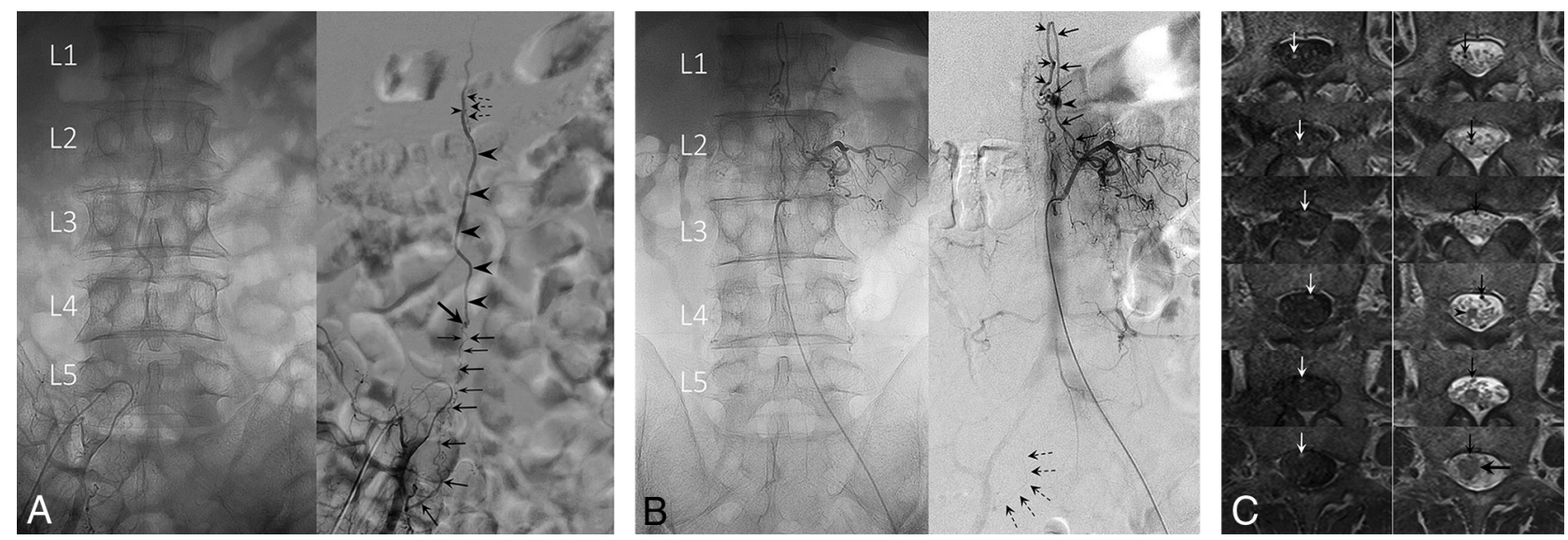

FIG 3. A, Unsubtracted (left) and subtracted (right) angiograms of the right internal iliac artery. A radicular artery (large arrows) originating from the right S1 lateral sacral artery forms a fistula (oblique arrow) at the L4 level. Note a second small feeder contributing to the fistula (small arrows). The straight ascending draining vein (arrowheads) opens into the perimedullary vein at the L1 level (small arrowhead), demonstrated by the opacification of superficial pial veins (dashed arrows). This finding suggests that the draining vein is a radicular vein. The ASA had no contribution to the fistula (not shown). B, A coexisting L1 level perimedullary AVF supplied from the left L2 radiculopial artery (arrows). An aneurysm (arrowhead) is seen at the fistulous site (small arrow). Note the faint opacification of the right S1 lateral sacral artery, identical to that seen in A, supplying the L4 level fistula (dashed arrows). Note the descending, then ascending draining vein that is separate from the right S1 radicular AVF. C, Serial thin-section gadolinium-enhanced TIWI (left column) and T2WI (right column) arranged in caudal (upper) to cranial (lower) order show the draining vein (arrows) is off the cord at the apex of the conus medullaris (arrowhead). The draining vein eventually merges with the spinal cord at a higher level (large horizontal arrow). This finding suggests that the draining vein is a radicular vein.
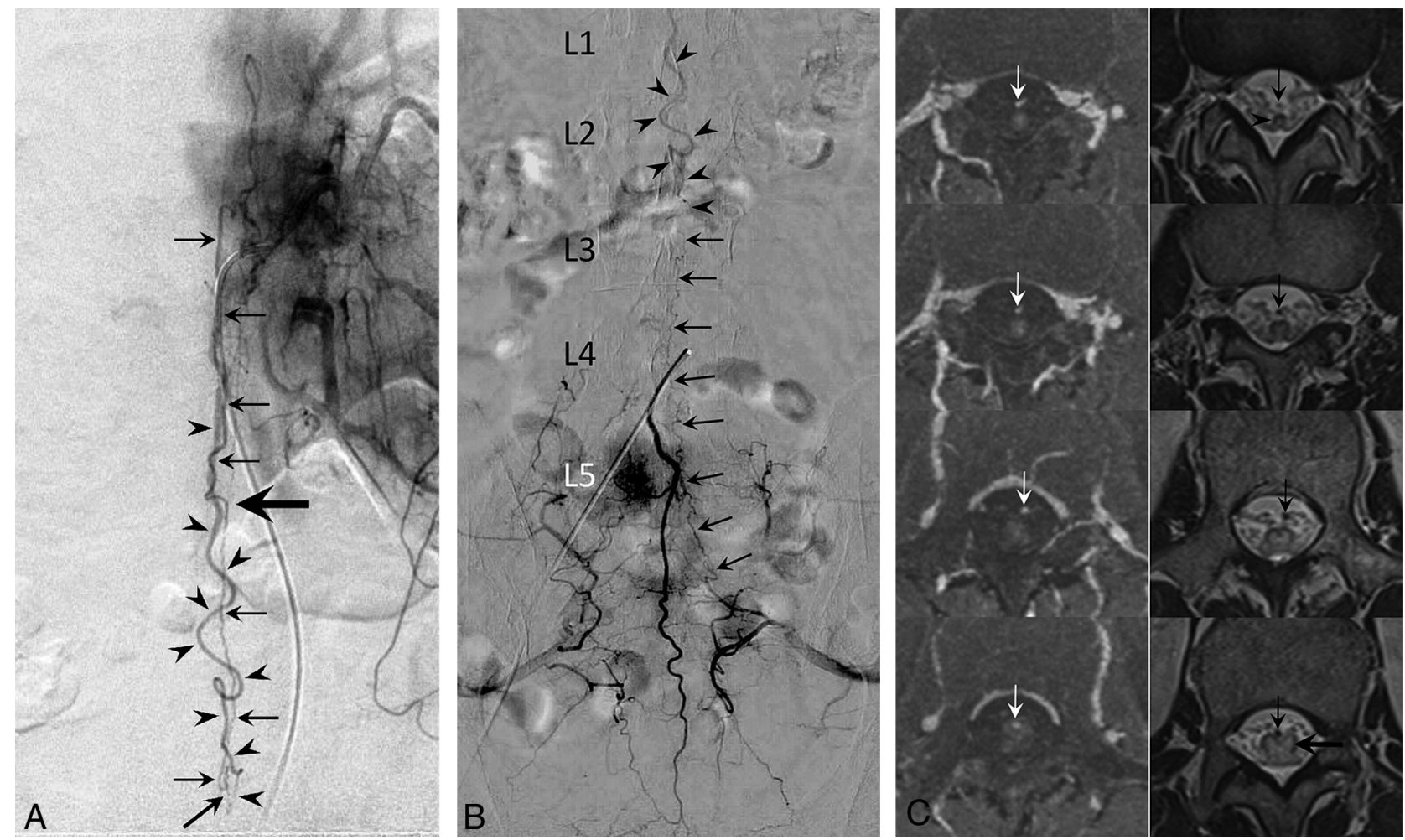

FIG 4. A, Angiogram of the left T11 intercostal artery in anteroposterior view demonstrates a posterior spinal artery supplying the anterior spinal artery (arrows) via the vasa corona. The ASA extends caudally to form a fistula at the L3 level (oblique arrow). The ascending draining vein shows a characteristic wavy pattern (arrowheads). Note the change in course and caliber of the descending ASA at the apex of the conus medullaris, suggesting a switch in the ASA to a radicular artery (large horizontal arrow). B, Medial sacral artery angiogram in anteroposterior view demonstrates anastomotic opacification of the radicular artery (arrows) from the left S1 lateral sacral artery supplying the L3 level AVF. The same draining vein seen in $A$ is detected in this study (arrowheads). The L3 AVF in this patient has a dual supply from the ASA and an S1 radicular artery. C, Serial thin-section gadolinium-enhanced TIWI (left column) and T2WI (right column) arranged in caudal (upper) to cranial (lower) order show the draining vein (arrows) is off the cord at the apex of the conus medullaris (arrowhead). The draining vein eventually merges with the spinal cord at the L1 level (large horizontal arrow). This finding suggests that the draining vein is a radicular vein. 
embolization. Also, the vascular anatomy may prefer direct surgery over an endovascular approach because of a long and narrow feeding artery. More important, treatment to a radicular nerve carries a higher risk of neuronal damage than a functionally dormant FT. Therefore, embolization of a cauda equina AVF should be carried out with discretion.

\section{LIMITATIONS}

The small case number and lack of surgically confirmed AVF except in 1 case prevent us from reaching definitive conclusions. To overcome these shortcomings, we recruited definitive AVF cases from the literature and added the venous information by thin-section axial MR imaging studies. Nevertheless, surgically confirmed cauda equina and FT AVFs were limited to 3 and 31 cases, respectively. Although the number was limited, MR imaging seemed a promising method that may be added to the existing diagnostic technique in the future.

\section{CONCLUSIONS}

Cauda equina AVF and FT AVF may be radiologically differentiated by combining the characteristic arterial and venous features.

Disclosures: None.

\section{REFERENCES}

1. Olry R, Haines DE. Between André Du Laurens' horse tail and William Cadogan's pony tail. J Hist Neurosci 2012;21:327-31 CrossRef Medline

2. Djindjian $\mathrm{M}$, Djindjian R, Rey A, et al. Intradural extramedullary spinal arterio-venous malformations fed by the anterior spinal artery. Surg Neurol 1977;8:85-93 Medline

3. Ohtonari T, Ota S, Nishihara N, et al. Arteriovenous fistula in a nerve root of the cauda equina fed by a proximal radiculo-medullary artery: a report of two cases. Interv Neuroradiol 2011;17:217-23 CrossRef Medline

4. Hong T, Park JE, Ling F, et al. Comparison of 3 different types of spinal arteriovenous shunts below the conus in clinical presentation, radiologic findings, and outcomes. AJNR Am J Neuroradiol 2017;38:403-09 CrossRef Medline

5. Tanioka S, Toma N, Sakaida H, et al. A case of arteriovenous fistula of the cauda equina fed by the proximal radicular artery: anatomical features and treatment precautions. Eur Spine J 2018;27:281-86 CrossRef Medline

6. Gueguen B, Merland JJ, Riche MC, et al. Vascular malformations of the spinal cord: intrathecal perimedullary arteriovenous fistulas fed by medullary arteries. Neurology 1987;37:969-79 CrossRef Medline

7. Meisel HJ, Lasjaunias P, Brock M. Modern management of spinal and spinal cord vascular lesions. Minim Invasive Neurosurg 1995;38:13845 CrossRef Medline

8. Tender GC, Vortmeyer AO, Oldfield EH. Spinal intradural arteriovenous fistulas acquired in late adulthood: absent spinal venous drainage in pathogenesis and pathophysiology. Report of two cases. J Neurosurg Spine 2005;3:488-94 CrossRef Medline

9. Mitha AP, Murphy EE, Ogilvy CS. Type A intradural spinal arteriovenous fistula. Case report. J Neurosurg Spine 2006;5:447-50 CrossRef Medline

10. Jin YJ, Kim KJ, Kwon OK, et al. Perimedullary arteriovenous fistula of the filum terminale: case report. Neurosurgery 2010;66:E219-20 CrossRef Medline
11. Kumar A, Deopujari CE, Mhatre M. Misdiagnosis in a case of noncompressive myelopathy due to a lumbar spinal intradural fistula supplied by the artery of Adamkiewicz. Surg Neurol Int 2011;2:12 CrossRef Medline

12. Witiw CD, Fallah A, Radovanovic I, et al. Sacral intradural arteriovenous fistula treated indirectly by transection of the filum terminale: technical case report. Neurosurgery 2011;69:E780-84 CrossRef Medline

13. Trinh VT, Duckworth EA. Surgical excision of FT arteriovenous fistulae after lumbar fusion: Value of indocyanine green and theory on origins (a technical note and report of two cases). Surg Neurol Int 2011;2:63 CrossRef Medline

14. Lim SM, Choi IS, David CA. Spinal arteriovenous fistulas of the filum terminale. AJNR Am J Neuroradiol 2011;32:1846-50 CrossRef Medline

15. Takami T, Yamagata T, Mitsuhashi Y, et al. Direct surgery for spinal arteriovenous fistulas of the filum terminale with intraoperative image guidance. Spine 2012;37:E1524-28 CrossRef Medline

16. Fischer S, Aguilar Perez M, Bassiouni H, et al. Arteriovenous fistula of the filum terminale: diagnosis, treatment, and literature review. Clin Neuroradiol 2013;23:309-14 CrossRef Medline

17. Chanthanaphak E, Pongpech S, Jiarakongmun P, et al. Filum terminale arteriovenous fistulas: the role of endovascular treatment. $J$ Neurosurg Spine 2013;19:49-56 CrossRef Medline

18. Krishnan P, Banerjee TK, Saha M. Congestive myelopathy (FoixAlajouanine syndrome) due to intradural arteriovenous fistula of the filum terminale fed by anterior spinal artery: case report and review of literature. Ann Indian Acad Neurol 2013;16:432-36 CrossRef Medline

19. Takeuchi M, Niwa A, Matsuo N, et al. Pathomorphological description of the shunted portion of a filum terminale arteriovenous fistula. Spine J 2014;14:e7-10 CrossRef Medline

20. Sharma P, Ranjan A, Lath R. Arteriovenous fistula of the filum terminale misdiagnosed and previously operated as lower lumbar degenerative disease. Asian Spine J 2014;8:365-70 CrossRef Medline

21. Ding D, Law AJ, Scotter J, et al. Lumbar disc herniation exacerbating venous hypertension from a spinal perimedullary arteriovenous fistula of the filum terminale. J Neurol Sci 2016;369:276-77 CrossRef Medline

22. Li J, Li G, Bian L, et al. Concomitant lumbosacral perimedullary arteriovenous fistula and spinal dural arteriovenous fistula. World Neurosurg 2017;105:1041.e7-1041-e14 CrossRef Medline

23. Hong T, Yu JX, Liu W, et al. Filum terminale arteriovenous fistulas with multiple shunt points: a report of two exceptional cases. World Neurosurg 2018;118:235-39 CrossRef Medline

24. Takai K, Komori T, Taniguchi M. Angioarchitecture of filum terminale arteriovenous fistulas: relationship with a tethered spinal cord. World Neurosurg 2019;122:e795-804 CrossRef Medline

25. Scullen T, Mathkour M, Amenta PS, et al. Arteriovenous fistula of the filum terminale: a case report and review of the literature. World Neurosurg 2019;130:42-49 CrossRef Medline

26. Djindjian M, Ribeiro A, Ortega E, et al. The normal vascularization of the intradural filum terminale in man. Surg Radiology Anat 1988;10:201-09 CrossRef Medline

27. Streeter GL. Factors involved in the formation of the filum terminale. Am J Anat 1919;25:1-12 CrossRef

28. Kunitomo K. The development and reduction of the tail and of the caudal end of the spinal cord in the human embryo. In: Contributions to Embryology. Carnegie Institution of Washington; 1918:8

29. Parke WW, Gammell K, Rothman RH. Arterial vascularization of the cauda equina. J Bone Joint Surg Am 1981;63:53-62 Medline

30. Crock HV, Yamagishi M, Crock MC. The Conus Medullaris and Cauda Equina in Man. An Atlas of the Arteries and Veins. SpringerVerlag; 1986:2 